\title{
Futbolcuların Topla ve Topsuz Yapılan Antrenmanlara Yönelik Görüşlerinin Belirlenmesi*
}

\author{
Mehmet YILDIZ **
}

Bilal ÇANDIR ***

\begin{abstract}
Özet
Futbolda özellikle aerobik kapasite ve anaerobik eşiğin topla yapılan çalışmalarda istenilen yüklenme şiddetine ulaşılamayacağı düşünüldüğünden, dayanıklılığın geliştirilmesinde topsuz yapılan koşular ve interval çalışmalar önerilmektedir. Fakat futbolcuların topsuz yapılan bu tip çalışmalara yönelik görüşleri henüz netlik kazanmamıştır. $\mathrm{Bu}$ araştırmanın amacı; futbolcuların topla ve topsuz yapılan antrenmanlarla ilgili görüşlerini belirlemektir. Yapılan araştırmaya Afyonkarahisar ilinde bulunan ve süper amatör kümede oynayan yüz kırk beş futbolcu (yaş: $22.70 \pm 4.53$ yıl; antrenman yaşı: $8.94 \pm 2.01$ yıl) katılmıştır. Araştırmada futbolcuların demografik bilgilerinin yanında, topla ve topsuz yapılan antrenmanlarla ilgili görüşlerinin belirlenmesine yönelik sorular sorulmuştur. Futbolcuların \%17'si topsuz antrenmanı sevmediğini, \%9.7'si ise nefret ettiğini bildirmiş̧ir. Bunun yanında \%24,1'i normal şiddete ve sürede topsuz antrenmanı tercih ederken, \%75.9'u daha yüksek şiddette ve uzun sürede topla yapılan antrenmanı tercih edeceğini bildirmiştir. Sonuç olarak futbolcuların topla yapılan antrenmanlarda antrenmanın şiddeti yüksek ve süresi uzun olsa da topla yapılan antrenmanları daha fazla istedikleri görülmüştür. Literatürde topla yapılan dar alan oyunları ve drillerdeki yüklenme şiddetinin topsuz antrenmana göre daha yüksek olduğu bildirilmektedir. Futbolcuların topla yapılan çalışmalara olan isteklerinin motivasyon aracı olarak kullanılması ile antrenman sayısının düşük olduğu amatör takımlarda çalıştırıcıların futbolcularda fiziksel, teknik ve taktik özellikleri kombine bir şekilde geliştirebilmeleri için doğru şekilde planlanmış topla yapılan dar alan oyunları ve drilleri kullanmaları önerilmektedir.
\end{abstract}

Anahtar Kelimeler: Futbol, Topsuz antrenman, Yüklenme şiddeti

\section{Determination of the Opinions of the Soccer Players Regarding the Training With and Without Balls}

\begin{abstract}
Running and interval exercises without a ball is an important part of the training in football. Since aerobic capacity and anaerobic threshold cannot be achieved in trainings performed with the ball, it is recommended that running and interval based exercises without a ball are performed to improve endurance. However, the opinions of footballers about this type of exercises without a ball have not been clarified yet. The purpose of this study was to determine the opinions of football players regarding exercises without a ball. 145 soccer players (age: $22.70 \pm 4.53$ years; training age: $8.94 \pm 2.01$ years) in Afyonkarahisar province participated in the current study. In addition to demographic information, questions were asked to determine the opinions of the players about the exercises with and without balls. $17 \%$ of football players reported that they did not like to train without balls while $9.7 \%$ of them reported that they hate that. In addition, while $24.1 \%$ preferred to exercise without a ball during normal intensity and duration, $75.9 \%$ reported that they would prefer training

\footnotetext{
* Bu çalışma 2. Uluslararası Spor Bilimleri, Turizm ve Rekreasyon Kongresinde sözel bildiri olarak sunulmuştur

** Dr. Ögretim Üyesi1, Afyon Kocatepe Üniversitesi1, Beden Eğitimi ve Spor Yüksekokul Okulu, Afyonkarahisar, Türkiye, mehmetyildiz@aku.edu.tr

*** Öğrenci, Afyon Kocatepe Üniversitesi1, Beden Eğitimi ve Spor Yüksekokul Okulu, Afyonkarahisar, Türkiye, bcandır003@hotmail.com
} 
with a ball in higher intensity and longer duration. As a result, it was seen that football players wanted to conduct training with a ball more even if the training was high intensity and the duration was long. It has been reported in the related literature that the load intensity of small side games and drills is higher in exercises with a ball than the exercises without a ball. It is suggested that amateur teams with low training numbers should use correctly planned small side games and drills in order to improve the physical, technical and tactical characteristics of footballers in combination using their opinions regarding exercises with a ball as a motivation tool.

Keywords: Football, Opinion, Without a ball, Training intensity

\section{GİRIŞ}

Futbolda performans birçok faktöre bağlıdır. Bunların içinde de teknik beceri ve dayanıklılık kapasitesi müsabaka performans1 üzerine etki eden en önemli faktörlerin başında gelmektedir (Bangsbo, 1994) . Aerobik dayanıklılik performans1 maksimal oksijen tüketimi(VO2 max), anaerobik eşik ve iş ekonomisi şeklinde üç ana unsura dayanır. VO2 max büyük kas grupları tarafindan ortaya konan dinamik egzersizlerde alınan en yüksek oksijen miktarı olarak tanımlanır. Geçmiş çalışmalara bakıldığında VO2 max ile müsabaka süresince kat edilen mesafe arasında önemli derecede ilişki olduğu ortaya konmuştur. $\mathrm{Ne}$ var ki, futbolcuların dayanıklılık kapasiteleri geleneksel olarak, topsuz koşu drillerinden oluşmaktadır (Aguiar ve ark., 2012).

Bunun en büyük nedeni topla yapılan futbol oyun ve drillerinin yeteri kadar fiziksel yüklenme yapmadığı inancıdır (Helgerud ve ark., 2001; Wisloff ve ark., 1998). Fakat futbolda dayanıklılık için dar alan futbol drilleri üzerine yapılan birçok çalışmada yüksek yoğunluğa ulaşıldığı bildirilmiştir (Billat, 2001; Reilly ve White, 2004). Koşu aktiviteleri her ne kadar futbolcular tarafindan tercih edilmese de VO2 max gelişimi için uygun şiddette egzersiz yüklemesinin sadece futbol egzersizleri ile geliştirilemeyeceği bildirilmiştir (Hoff ve ark., 2002). Helgerud ve ark. (2001) topsuz yapilan interval egzersizleri ile yüklenme şiddetinin kalp atım monitörleri ile rahatlıkla gözlenebileceğini, fakat futbol etkinliğinde rakibe ya da kendi takım arkadaşına odaklanma, top kontrolü, müsabaka durumu ya da antrenmanın yarattığ stresin yüklenme şiddetini düşürebileceğini belirtmiştir (Helgerud ve ark., 2001; Wisloff ve ark., 1998). Literatürde futbola özgü çalışmalardaki şiddetin futbolcularda mutlaka nabız ya da oksijen tüketim ilişkisi ile ele alınması gerektiği vurgulanmıştır (Blix ve ark., 1974; Herd, 1991). Helgerud ve ark. (2001) 9 hafta, haftada iki gün, dört set ve her sette dört dakika yüksek şiddetli egzersiz (maksimal kalp atımının \%90-95'inde maksimal tepe yukarı koşu) ve setler arası maksimal kalp atımın \%'70inde aktif dinlenme ile maksimal oksijen tüketiminde $\% 11$ 'lik gelişim olduğunu bildirmiştir. $\mathrm{Bu}$ gelişimi müsabaka süresince $\% 20$ 'lik kat edilen mesafe gelişimi, topla yapılan hareketler de \%23'lük artış ve sprintlerde $\% 100$ 'lük artış takip etmiştir. Futbolda topsuz olarak yapılan koşular ve intervaller antrenmanların önemli bir kapsamını oluşturmaktadır. Özellikle aerobik kapasite ve anaerobik eşiğin toplu çalışmalarda istenilen yüklenme şiddetine ulaşılamayacağı düşünüldüğünden bu tip çalışmalarda topsuz yapılan koşular ve interval çalışmalar önerilmektedir (Hoff,ve ark., 2002; Helgerud ve ark., 2001).

Her ne kadar kondisyon amaçlı yapılan futbola özgü drillerde bazı oyuncuların düşük yoğunlukta yüklenmeye maruz kaldığ 1 düşünülse son zamanlarda yapılan çalışmalarda iyi organize edildiğinde farklı oyuncuların benzer yüklenmeye maruz kaldıkları gösterilmiştir (Little ve Williams, 2006; Little ve Williams, 2007; Rampinini ve ark., 2007). Bununla birlikte teknik ve dayanıklılık kapasitelerinin topla yapilan futbol oyun dirilleri kullanılarak aynı anda antrene edilmesi gerek zaman kazancı gerekse de fiziksel yüklenme açısından en etkili yöntem olacağ 1 önerilmiştir. Futbola özgü toplu drillerin kombine teknik ve fizyolojik antrenmanla birleşmesinden oluşan antrenmanlarin topsuz yapilan kondisyon çalışmalarına oranla bilinen açık etkilerinin yanında sporcuların motivasyonlarını arttırdığı varsayılmaktadır (Little, 2009). Her ne kadar futbolcuların topsuz yapilan çalışmaları daha sıkıcı buldukları varsayılsa 
da ilgili literatürde bununla ilgili olarak sınırlı sayıda bilgi bulunmaktadır. $\mathrm{Bu}$ çalışmada futbolcularin topla ve topsuz yapilan antrenmanlarda gerek antrenman şiddetinin yüksekliği gerekse de antrenman süresinin uzunluğuna bakmaksızın topla yapılan antrenmanları tercih edeceği hipotez edilmiştir.

\section{Çalışmanın Amacı}

$\mathrm{Bu}$ çalışmanın amacı futbolcuların toplu ve topsuz yapilan antrenmanlarla ilgili görüşlerinin belirlenmesidir.

\section{YÖNTEM}

\section{Katılimcılar}

Çalışmaya Afyonkarahisar ilinde bulunan ve süper amatör kümede oynayıp haftada 3-4 gün/1-2 saat antrenman yapan 145 erkek

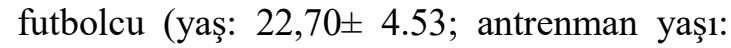
$8,94 \pm 2.01)$ gönüllü olarak rastgele yöntemle katılmıştır. Katılımcıların tamamı çalışma öncesi gönüllü olur formunu doldurmuştur.

\section{Veri toplama aract}

Sporcularin toplu ve topsuz yapilan çalışmalara yönelik görüşlerinin belirlemesi amacıyla kısa bir anket düzenlenmiştir. Anket çalışmasında toplam yedi soru sorulmuştur. Demografik bilgiler kısmında katılımcıların yaş, antrenman yaşları, hafta da kaç gün antrenman yaptığ 1 , bir antrenman süresinin ne kadar olduğunun belirlenmesi 4 soru, topla ve topsuz yapilan antrenmanlarla ilgili görüşlerinin belirlenmesi için de üç soru sorulmuştur.

\section{Verilerin analizi}

İstatistiksel analiz için SPSS paket programı kullanılmıştır. Ankette sorulan sorulara yönelik verilen cevaplar frekans ve yüzdelik değerler ile değerlendirilmiştir.

\section{BULGULAR}

Tablo 1'de görüldüğü üzere topsuz antrenmanı çok seviyorum diyen futbolcuların oran1 \%13,1 $(\mathrm{f}=19)$, seviyorum diyenlerin oran1 \%36.6( $\mathrm{f}=36,6)$, olsa da olur olmasa da olur diyenlerin oran1 $\% 23,4(\mathrm{f}=34)$, sevmiyorum diyenlerin oran $\% 17,2$ (25) ve nefret ediyorum diyenlerin oran $\% 9,7(\mathrm{f}=14)$ şeklindedir.
Tablo 2'de görüldügü üzere katılımcıların topsuz ve topla yapılan çalışmalara karşı tutumlarının süre açısından karşılaştırmalarını istendiğinde, katılımciların \%24'ü $(\mathrm{f}=35)$ şiddeti aynı olan normal sürede (1 saat) biten topsuz antrenmmanı tercih ederken, katılımciların \% 75,9'u ( $\mathrm{f}=110)$ normal sürede biten topsuz antrenman yerine şiddeti ayn olan daha uzun süreli (1,5 saat) biten toplu antrenmanı tercih edeceğini bildirmiştir.

Tablo 3'de görüldüğg̈ üzere katılımcıların topsuz ve topla yapılan çalışmalara karşı tutumlarınınyüklenme şiddeti açısından karşılaştırmaları istendiğinde katılımcıların \%24'ü (f=35)normal şiddette topsuz antrenmanı tercih ederken, katılımciların $\% 75,9$ 'u $(\mathrm{f}=110)$ normal şiddetli topsuz antrenman yerine yüksek şiddette toplu antrenmanı tercih edeceklerini bildirmiştir.

Tablo 1. Katılımciların topsuz yapılan Çalışmalarla ilgili fikirlerinin frekans ve yüzde Dağılımları

\begin{tabular}{lll}
\hline Değişkenler & $\mathrm{f}$ & $\%$ \\
\hline Çok seviyorum & 19 & 13.1 \\
\hline Seviyorum & 53 & 36.6 \\
\hline Olsa da olur , Olmasa da olur & 34 & 23.4 \\
\hline Sevmiyorum & 25 & 17.2 \\
\hline Nefret ediyorum & 14 & 9.7 \\
\hline Total & 145 & 100 \\
\hline
\end{tabular}

f=frekans, \%=yüzde

Tablo 2: Katılımciların topsuz ve topla yapılan çalışmalara karşı fikirlerinin süre açısından karşılaştırmalarını gösteren frekans ve yüzde değerleri

\begin{tabular}{lll}
\hline Değişkenler & f & $\%$ \\
\hline $\begin{array}{l}\text { Şiddeti aynı olan normal sürede (1 } \\
\text { saat) biten topsuz antrenmman mı? }\end{array}$ & 35 & 24.1 \\
\hline $\begin{array}{l}\text { Şiddeti aynı olan daha uzun süreli } \\
\text { (1,5 saat) biten toplu antrenmman }\end{array}$ & 110 & 75.9 \\
mi? & & \\
\hline Total & 145 & 100 \\
\hline
\end{tabular}

f=frekans, \%=yüzde 
Tablo 3: Katılımciların topsuz ve topla yapılan çalışmalara karşı fikirlerinin yüklenme şiddeti açısından karşılaştırmalarını gösteren frekans ve yüzde değerleri

\begin{tabular}{lll}
\hline Değişkenler & $\mathrm{f}$ & $\%$ \\
\hline $\begin{array}{l}\text { Norma şiddette topsuz antrenman } \\
\text { mi? }\end{array}$ & 35 & 24.1 \\
\hline $\begin{array}{l}\text { Yüksek şiddette toplu antrenman } \\
\text { mi? }\end{array}$ & 110 & 75.9 \\
\hline Total & 145 & 100 \\
\hline $\mathrm{f}=$ frekans, \%=yüzde & &
\end{tabular}

\section{TARTIŞMA ve SONUÇ}

$\mathrm{Bu}$ çalışmanın amacı futbolcuların toplu ve topsuz yapilan antrenmanlarla ilgili görüşlerinin belirlenmesidir. Çalışma sonunda futbolcularin topla yapilan antrenmanlarda antrenmanın şiddeti yüksek ve süresi uzun olsa da topla yapilan antrenmanları daha fazla istedikleri görülmüştür.

Futbolda fizyolojik, teknik ve taktik becerilerin önem arz ettiği ve antrenman planlamasının bu değişkenler üzerinde oynanarak yapıldığ 1 bilinmektedir. Literatürde her ne kadar topla yapılan çalışmalarda yüksek yüklenme şiddetinin yakalanamayacağı bildirilse de (Helgerud ve ark., 2001; Wisloff ve ark., 1998; Hoff ve ark., 2002), doğru planlama yapıldığında topla yapılan dar alan oyunları ve drillerde yüklenme şiddetinin topsuz antrenmana göre daha yüksek olduğu görülmektedir (Reilly, 2005) . Örneğin; Reilly ve Ball (1984) futbolcuları iki gruba ayırıp bir grubu koşu bandında şiddeti gittikçe hızlanan bir protokolle koşturmuşlardır. Aynı şekilde diğer grup ise aynı koşu hızında top sürerek koşuyu gerçekleştirmişlerdir. Çalışma sonunda her iki gurubun harcadikları enerji, kan laktat değerleri ile yorgunluk algıları karşılaştırılmıştır. Çalışma sonunda yüklenme şiddetinin topla koşu yapan grupta daha fazla olduğu bildirilmiştir. Çalışmadan da anlaşılacağ 1 gibi top ile yapılan çalışmalarda futbolcuların topa olan ilgilerinden dolay daha fazla yüklenme şiddetine ulaşıldı ̆̆ 1 düşünülmektedir. Bu tip fiziksel antrenmanlar teknik antrenmanlarda birleştirildiğinde sporcular açsından da zaman tasarrufu sağlamaktadır (Reilly, 2005). Bir diğer çalışmada İngiltere Premier ligi takımlarının genç klasmanda oynayan futbolcular iki gruba ayrılmıştır. Birinci grup klasik interval şeklinde 6 hafta boyunca haftada 3 gün 4 set $\mathrm{X}$ 4dk. koşu, $3 \mathrm{dk}$. aktif dinlenme gerçekleşirken, diğer grup aynı süre şiddette antrenörün gözetiminde ve cesaretlendirmesiyle $5 \times 5$ dar alan oyunu oynamışlardır. Çalışma sonunda her iki gurubun da aerobik kapasite ve laktat profilleri benzerlik göstermiştir.

Bir müsabaka süresince teknik standartları devam ettirmek ve müsabakanın fiziksel ihtiyaçlarını karşılayabilmek için sporcular yüksek bir fitness düzeyine sahip olmalıdırlar. Düzenli olarak müsabaka yapmak sporcunun fitness düzeyinin devamına yardımcı olur. Fakat ek olarak fitness antrenmanları gereklidir. Çalışmalarda topun olması futbolda kullanılan kasların çalışmasını sağlayarak ve sporcuların motivasyonunu arttırmaktadır (Bangsbo,1995). Sporculardaki topla yapılan antrenmanlara karşı olan motivasyonun etkisiyle daha yüksek şiddetli ve daha uzun süreli antrenmanlar planlanmas1 sadece teknik gelişim değil aynı zamanda sporcuların dayanıklık kapasitelerinin de daha fazla gelişmesine olanak sağlayabilir.

Sonuç olarak futbolcuların topla yapılan antrenmanlarda antrenmanın şiddeti yüksek ve süresi uzun olsa da topla yapılan antrenmanları daha fazla istedikleri görülmüştür. Literatürde topla yapılan dar alan oyunları ve drillerdeki yüklenme şiddetinin topsuz antrenmana göre daha yüksek olduğu bildirilmektedir. Futbolcuların topla yapılan çalışmalara olan isteklerinin motivasyon arac1 olarak kullanılmasi ile antrenman sayısının düşük olduğu amatör takımlarda çalıştırıcıların futbolcularda fiziksel, teknik ve taktik özellikleri kombine bir şekilde geliştirebilmeleri için doğru şekilde planlanmış topla yapılan dar alan oyunlar1 ve drilleri kullanmalar1 önerilmektedir. $\mathrm{Bu}$ tip egzersizler koşu, ağırlı antrenmanı, esneklik egzersizleri, pliometrikler ve çeviklik drilleri gibi egzersiz modellerinin yapılmaması anlamına gelmemektedir. 


\section{KAYNAKÇA}

Aguiar, M., Botelho, G., Lago, C., Maças, V., \& Sampaio, J. (2012). A review on the effects of soccer small-sided games. Journal of human kinetics, 33, 103-113.

Bangsbo, J. (1994). Fitness training in football: a scientificapproach.

AugustKroghInst.,University of Copenhagen.

Billat, L. V. (2001). Interval training for performance: a scientific and empirical practice. Sports Medicine, 31(1), 13-31.

Helgerud, J.,Engen, L. C., Wisloff, U., \&Hoff, J. (2001). Aerobic endurance training improves soccer performance. Medicine and science in sports and exercise, 33(11), 1925-1931.

Hoff, J.,Wisløff, U., Engen, L. C., Kemi, O. J., \&Helgerud, J. (2002). Soccer specific aerobic endurance training. British journal of sports medicine, 36(3), 218221

Little, T.,\& Williams, A. G. (2006). Suitability of soccer training drills for endurance training. TheJournal of Strength \& Conditioning Research, 20(2), 316-319.

Little, T.,\& Williams, A. G. (2007). Measures of exercise intensity during soccer training drills with Professional soccer players. The Journal of Strength \& Conditioning Research, 21(2), 367-371., 2007

Little, T. (2009). Optimizing theuse of soccer drills for physiological development. Strength \& Conditioning Journal, 31(3), 67-74.

Rampinini, E.,Impellizzeri, F. M., Castagna, C., Abt, G., Chamari, K., Sassi, A., \&Marcora, S. M. (2007). Factors influencing physiological responses to small-sided soccer games. Journal of sports sciences, 25(6), 659-666.

Reilly, T.,\&Ball, D. (1984). The net physiological cost of dribbling a soccer ball. Research Quarterly for Exercise and Sport, 55(3), 267-271.

Reilly, T.,\& White, C. (2005). Small-sided games as an alternative to interval-training for soccer players. Science and football $\mathrm{V}, 355-8$.
Sassi, R.,Reilly, T., \&Impellizzeri, F. (2005). A comparison of small-side games and interval training in elite Professional soccer players. Science and football V. Oxon: Routledge, 352-4.

Wisloeff, U. L. R. I. K.,Helgerud, J., \&Hoff, J. (1998). Strength and endurance of elite soccer players. Medicine and science in sports and exercise, 30, 462-467. 